\title{
Religious Character and Service Innovation toward the Improvement of Sustainable Quality of Primary Health Services in South Sulawesi
}

\author{
Muhammad Tahir ${ }^{1}$, Ridwan Amiruddin ${ }^{2}$, Sukri Palutturi ${ }^{3}$, Fridawaty Rivai ${ }^{4}$, Lalu Muhammad Saleh $^{5}$ \\ ${ }^{1}$ Doctoral Students of Public Health at Hasanuddin University and Stikes Muhammadiyah Sidrap, ${ }^{2}$ Department of \\ Epidemiology Faculty of Public Health Hasanuddin University, ${ }^{3}$ Department of Health Policy and Administrative \\ Faculty of Public Health Hasanuddin University, ${ }^{4}$ Department of Hospital Management and Administration \\ Faculty of Public Health Hasanuddin University, ${ }^{5}$ Department of Occupational Health and Safety
}

\begin{abstract}
The World Health Organization (WHO) stated that accreditation is a method for ensuring quality of health services. The method was developed in Indonesia. Accreditationis a form of method to measure the quality of health center services. Malcolm Baldrige National Quality Award (MBNQA) model and The Model For Understanding Success in Quality (MUSIQ) that are developed in several countries, have not paid attention to the religious and service innovation aspects. This study was aimed to analyze the influence of religious character and service innovation toward the improvement of sustainable quality of primary health services in South Sulawesi. This research was a mixed method research. The qualitative data was obtained from 10 informants that the result was then examined by using content analysis. The samples for quantitative study were chosen through proposive stratified random sampling technique with Lame show formula to get 395 respondents.

From the result of qualitative research, it was found that religious characters have 10 indicators, namely discipline, presenting God in every activity, fair, patient, friendly, committed, tabliqh, fathanah, amanah and shiddiq. In addition, service innovation is composed of 6 indicators namely new activities/modifications, follow-up analysis, resource support, cross-sector collaboration, providing new brands and developing local wisdom.

Furthermore, from the result of quantitative research, it was found that there was a significant influence of religious character and service innovation toward the improvement of sustainable quality of primary health services by using Chi-Square test result which $p$ value $=0.001(p<0.05)$. Hence, it is recommended that community health service staff should apply religious character and service innovation to improve sustainable quality of primary health care.
\end{abstract}

Keywords: Religious character, innovation, service quality.

\section{Introduction}

Accreditation is a form of assessment or evaluation of the quality and feasibility of an institution conducted by an accreditation body. The World Health Organization (WHO) uses this system to evaluate the process of health services in improving the quality of services to serve patients. WHO expects all countries to have quality health services. ${ }^{1}$
Moreover, accreditation is a process of evaluation and monitoring through measurement of compliance with standards, not an end result of quality. The Institute of Medicine (IOM) reported that the quality improvement approach is more results-based. Therefore, accreditation is considered as the end of quality check so that efforts to improve quality have not been sustainable. ${ }^{2}$

Malcolm Baldrige National Quality Award (MBNQA) and The Model for Understanding Success 
in Quality (MUSIQ) are quality improvement concepts developed in many developed countries. One of the weaknesses is the lack of attention to aspects of religious character and service innovation. The success of the implementation is determined by multiple variables, and each of the variableis interconnected with each other. ${ }^{3}$ Community health center is still less than optimal in providing services to the community. This makes them prefer to get health services from clinic, hospital and other health facilities. In addition, the image and appearance of community health center far from government's attention.

Religious characters that must be owned by community health center staff are discipline, fair, honest, clean, trustworthy, good at communicating, patient, friendly, committed and wise. Thus, the staff should be able to apply those religious characters in the workplace in order to improve the sustainable quality. ${ }^{4}$

However, unsustainable quality of community health center services will result in low satisfaction of patients as well as a lack of trust. Therefore, efforts should be made to enhance the quality of community health center.

Religious Character: Religion, which is a particular system of belief, influences choices and behavior patterns of society. In fact, religion is a systematic culture that can create strong beliefs or values for its adherents. ${ }^{5}$

Developing health care employees' religious character will certainly have a positive impact on the ability to act in providing services to patients. This has been proven through several researches that the quality of Islamic-based service has a positive and significant impact on customer satisfaction. CARTER theory explains that there is a strong relationship between adherence to Islamic law and customer satisfaction. ${ }^{6}$ Cultural values, including customary norms, marriage values, loyalty values, and other values, are sacred for Indonesian people. ${ }^{7}$

The application of religious character in giving services is considered to be very important for Indonesian people for they are inseparable from the aspect of religion in acting. Religious principles thye hold are always applied in their daily activities.

Service Innovation: Innovation means creating changes or introducing new things. Innovating is transformating knowledge to be new products, processes and services, or can be said that it is the act of using something new. Innovation in public sector is more emphasized on the aspect of improvement resulted from innovation activities. ${ }^{8}$

Innovation ingiving service is aimed to make public services better and make it in accordance withplan. If innovation is only meant to adjust to the trend, it will not last forever. Thus, innovation must be sustainable so that it will change according to the needs and development of society.

Innovation in health services can lead to changes in better public health services. For institutions, it also will prove that they have a strong will to be better. However, creating service innovation is not easy. An organization that is able to see itself as a public servant would be able to create innovation that are difficult for themselves but are beneficial to society.

Puskesmas (Community Health Center): The Regulation of the Minister of Health (PMK) No. 75 Year 2014 regulated that Community Health Center is one of the places to provide first-level health service facilities that have the responsibility to provide health services to the community in the work area that has been designated for either one or several sub-districts.

In carrying out the function, puskesmas has the authority to make plans based on the analysis of existing health problems in community and services needed. Moreover, it also carries out advocacy and dissemination of health policies, communication, information, education and community empowerment in health sector, involves the community to identify and solve problems about health faced at every level of community development in collaboration with other sectors, carries out technical guidance to the network of services and community-based health efforts, enhances the competency of Human Resources (HR), monitors the implementation of development of health knowledge, and records, reports and evaluates on access, quality and coverage of health services as well as provides recommendations regarding public health issues, including support for early alert systems and responses in preventingdisease. $^{9}$

Quality of Health Services: Quality, in this case, is the level of perfection of health services which on the one hand can satisfy the service users and other parties. The procedure of its implementation is in accordance with the code of ethics and the established standards. The quality 
of community health center services is a series of health service activities that meet the needs of both individuals and communities carried out by professionals according to the standards and codes of ethics. ${ }^{4}$

The quality of health service has a function to provide an assessment that refers to the level of perfection in providing health services in accordance with what is needed and expected by whoever needs health services. The better the fulfillment of people health care needs, the better the quality obtained in health services.

\section{Materials and Method}

This study is a mixed method research, which is an approach to investigate an object by combining qualitative and quantitative researches in a study ${ }^{10}$ to obtain more comprehensive, valid, reliable, and objective data. The qualitative stage was carried out through focus group discussions (FGD) and in-depth interviews. The data were analyzed by means of content analysis, data reduction, and interpretation. The quantitative stage was done through cross sectional analytic of observational study observational study.

The populations of this study are members of the primary health care accreditation commission, accreditation surveyors, accreditation consultants, academics, religious leaders, community health center heads, quality control team, administration and management personnel that are responsible for the public and individual health from each community health center. Furthermore, the qualitative research was done by selecting 10 informants who have met the requirements, while the samples for the quantitative research were selected through proposive stratified random sampling technique based on Lame show formula to get 395 from 2,020 respondents.

\section{Research Results}

The qualitative research was done by conducting focus group discussions (FGD) and indepth interviews toward 10 informants. The informant defined religious character as follows.
“... discipline is a part of religious character, a strong discipline based on religious principles will develop a strong sense of awareness in improving sustainable quality ..." (SM, 62 years old)

“....religious character emphasizes more on the nature of prophethood:fatanah, amanah, siddiq, and tabligh. As well as cleanl, orderly, discipline, punctual, right on target, and appropriate in providing health services..." (MYY, 41 years old)

“...religious character includes prayer on time, present God in all activities, committed, and show equality in giving serviceto men and women ......." (GM, 48 years old). “...more discipline in doing worship, presenting God in all activities and sincerity are religious characters ..." (SR, 55 years old)

“......... the most important part of religious character are discipline, honest, trustworthy, intelligent, present God in all activities, and friendly ..." (AB, 40 years old)

“.........religious character can be seen from sustainable service, honest, do not commit corruption, collusion and nepotism, smiles, greets others, and as what showed by the prophet,fatanah, trustworthy, siddiq and tabligh..." (AMS, 52 years old)

“........ .. discipline, responsible, honest, committed, have strong empathy, friendly, smile, greet others, not gender biased, not differentiate male and female in giving services, not differentiate people based on race and religion, and pray before giving service ...... ..” (SP, 47 years old $)$

“...... the characters had by individuals cannot be measured, such as patience, like to complain, not giving up, have high fighting spirit. As officers, they should be hard-working, discipline, istiqomah, concern on punishments and rewards, give services that are safe and do not differentaite people based on their ethnicities, religions, capacity, being honest and responsible ...... ..” (RA, 52 years old)

Based on the result of the focus group discussion (FGD) on religious characters, the result can be seen in the following graph. 


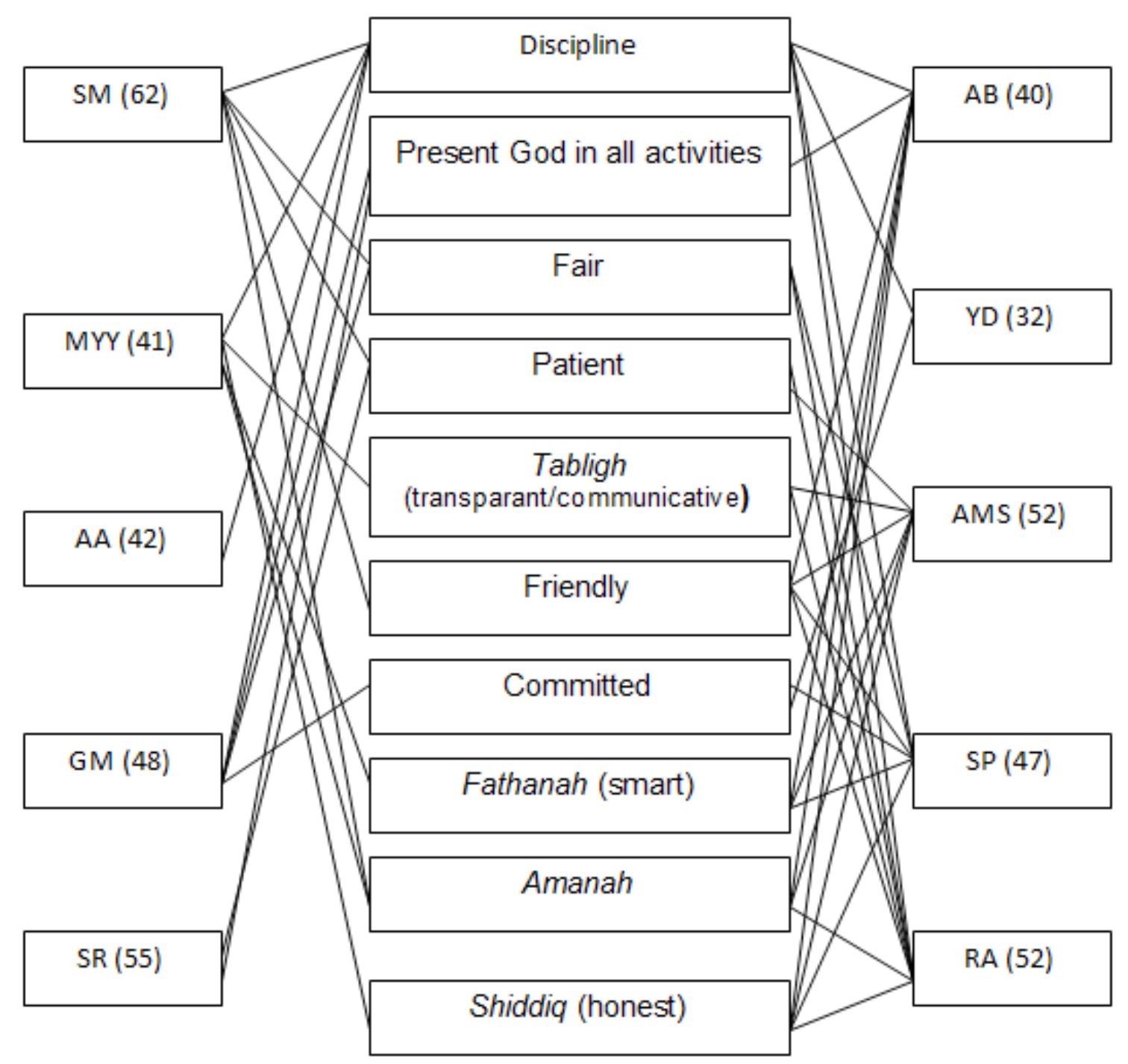

Figure 1. Schema of Religious Characters

Furthermore, the informants also explained about service innovation as follows.

"...... innovation is a follow-up to the results of the analysis of problems, changes in regulations, rules, or changes in technology. Innovation includes modification or new activities that are made by community health center. Innovation activities must also involve community participation ...... "(RP, 52 years old)

“........ New activities/modification of activities are aimed at improving services or achievements. As well as people, money, method, materials, and macines (resources), and local wisdom "(MYY, 41 years
“........ New activities or modification of activities, including making new terms that are attractive to the community, and also require a cross-sectoral role, and local wisdom of the community ......." (UM, 42 years old)

“..... The most important health service innovation includes brand, even though modification activities or new activities are carried out at the community health center... (AA, 42 years old)

Based on the result of the focus group discussions (FGD) and independent interviewon innovation in health services, a scheme is derivedand can be seen as follows. old) 


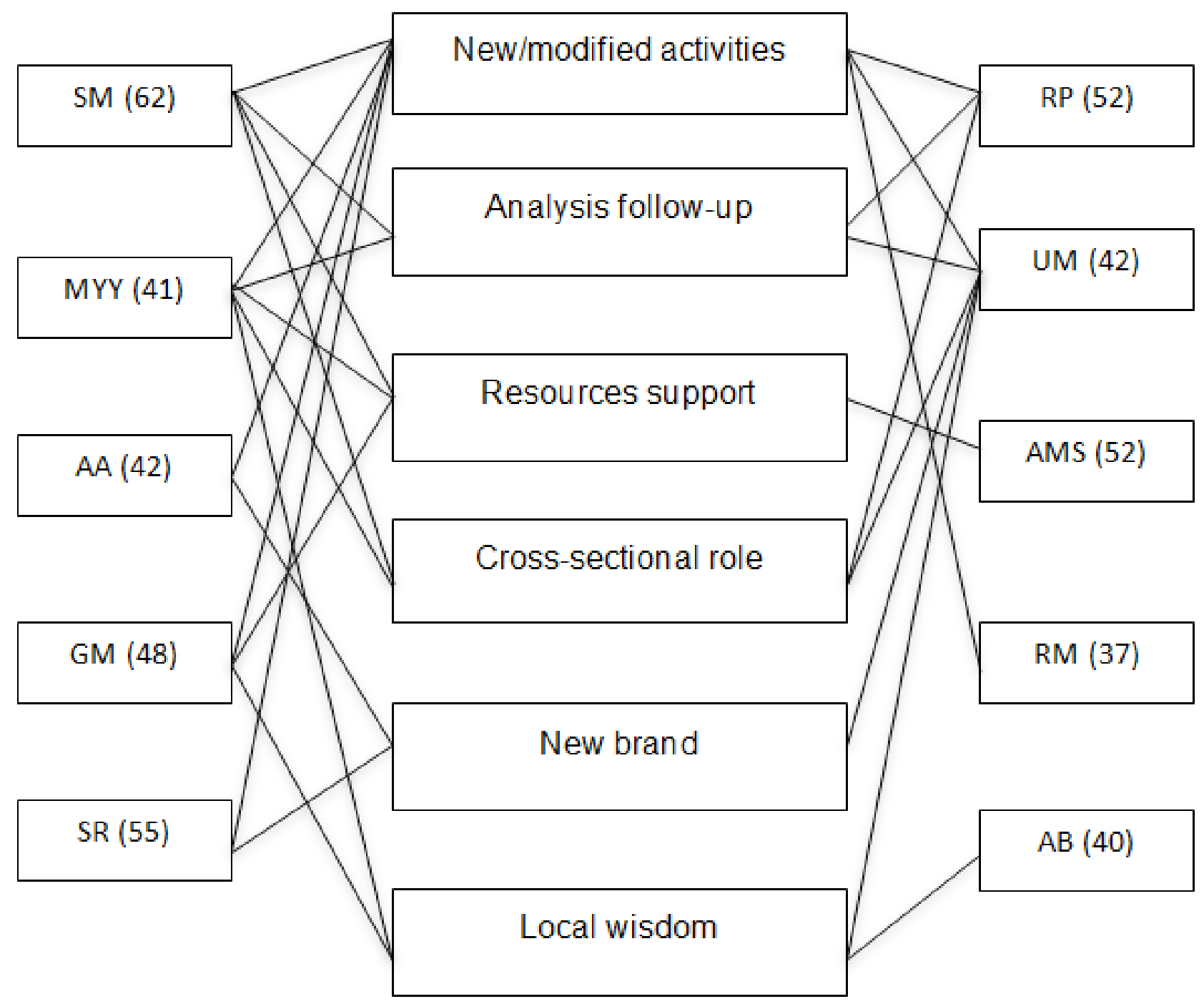

Figure 2. Health Service Innovation Scheme

From the qualitative research using questionnaire containing 140 statements filled by 395 respondents that was then analyzed, the result is presented as follows.
1. The Effect of Religious Characters toward the Improvement of Sustainable Quality of Primary Health Services.

Table 1. The Analysis Result of Religious Characters toward Improvement of Sustainable Quality of Primary Health Services in South Sulawesi

\begin{tabular}{|c|c|c|c|c|c|c|c|}
\hline \multirow{3}{*}{ Variable } & \multicolumn{4}{|c|}{ Sustainable Quality Improvement } & \multirow{2}{*}{\multicolumn{2}{|c|}{ Total }} & \multirow{3}{*}{ Result of Statistic Test } \\
\hline & \multicolumn{2}{|c|}{ Bad } & \multicolumn{2}{|c|}{ Good } & & & \\
\hline & $\mathbf{n}$ & $\%$ & $\mathbf{n}$ & $\%$ & $\mathbf{n}$ & $\%$ & \\
\hline \multicolumn{8}{|c|}{ Religious Characters } \\
\hline Fair & 155 & 80.7 & 37 & 19.3 & 192 & 100 & $p=0.001$ \\
\hline Good & 32 & 15.8 & 171 & 84.2 & 203 & 100 & \\
\hline
\end{tabular}

Source: Primary Data, 2019 
The improvement of the continuous quality of religious characters variable with bad category is hold by 37 people (19.3\%) and good category is hold by 171 people $(84.2 \%)$. The results of the data analysis by using Chi-square test obtained $p$ value $=0.001(p<0.05)$.
2. The Effect of Service Innovation toward the Improvement of Continuing Quality of Primary Health Services.

\section{Table 2: The Analysis Result of Service Innovation toward the Improvement of Sustainable Quality of Primary Health Services in South Sulawesi}

\begin{tabular}{|c|c|c|c|c|c|c|c|}
\hline \multirow{3}{*}{ Variable } & \multicolumn{4}{|c|}{ Sustainable Quality Improvement } & \multirow{2}{*}{\multicolumn{2}{|c|}{ Total }} & \multirow{3}{*}{ Result of Statistic Test } \\
\hline & \multicolumn{2}{|c|}{ Bad } & \multicolumn{2}{|c|}{ Good } & & & \\
\hline & n & $\%$ & $\mathrm{n}$ & $\%$ & $\mathbf{n}$ & $\%$ & \\
\hline \multicolumn{8}{|c|}{ Service Innovation } \\
\hline $\mathrm{Bad}$ & 120 & 79.5 & 31 & 20.5 & 151 & 100 & $p=0.001$ \\
\hline Good & 67 & 27.5 & 177 & 72.5 & 244 & 100 & \\
\hline
\end{tabular}

Source: Primary Data, 2019

According to the table above, the service innovation variable toward the improvement of sustainable quality that are categorized as bad is hold by 120 people $(79.5 \%)$ and that is categorized as good is hold by 67 people (27.5\%). In addition, the innovation service toward the improvement of sustainable quality that is categorized as good is hold by 31 people $(20.5 \%)$ while the one categorized as bad is hold by 177 people $(72.5 \%)$. The results data analysis by using Chi-square test obtained $\mathrm{p}$ value $=0.001(\mathrm{p}<0.05)$.

\section{Discussion}

According to the content analysis, data reduction, and interpretation of religious characters, there are 10 indicators, namely discipline, presenting God in every activity, fair, patient, friendly, committed, tabliqh, fathanah, amanah and shiddiq. Moreover, there are 6 indicators for health service innovation, namely new activities/modifications, follow-up analysis, resource support, cross-sector collaboration, providing new brands and developing local wisdom.

The results of the analysis of the religious characters variable showed that there were $84.2 \%$ of respondents stated that religious characters have good category toward the improvement of sustainable quality and have Chi Square test result with $p$ value of $0,000(p<0.05)$. This means that religious characters significantly influence the improvement of sustainable quality of primary health services in South Sulawesi.
The religious characters built in providing services can improve the sustainable quality of primary health care. Religious characters that must be owned by community health center officers are discipline, involve God in all activities, serve patients well (not gender, religious and racial biased, not distinguish patients' status), being friendly to anyone, and being fatanah (wise), amanah (trustworthy), siddiq (honest), and tabligh (communicative).

The results of the analysis of the service innovation variable showed that there were $72.5 \%$ of the respondents, stated that service innovation has good category toward the improvement of sustainable quality, the Chi Square test result obtained a $p$ value of $0.001(p<0.05)$. This means that service innovation significantly influencesthe improvement of sustainable quality of primary health services in South Sulawesi.

The service innovation of community health service from the analysis of problems, changes in regulations, changes in service guidelines or changes in technology will certainly be able to improve services. Service innovation in the form of new activity/modification, follow-up of problem analysis result, or development of local wisdom must get the support from resources and cross-sectional role. Those kinds of service innovationsare needed includng making new brands to increase community motivation and interest $\mathrm{t}^{11-13}$. 


\section{Conclusion}

Religious characters and service innovation have significant influence toward the improvement of sustainable quality of primary health services in South Sulawesi. Therefore, it is recommended that every officer in the community health center should apply religious characters and innovation in providing services to the community to improve the sustainable quality.

\section{Acknowledgment:}

Competing Interests: The researchers declare that they do not have any competing interest.

Financial Support: The funding of this research was carried out independently.

Ethical Clearance: The ethical approval of this research was based on the letter Number: 4326/ UN4.14.8/TP.02.02/2019 Faculty of Public Health, Hasanuddin University, Makassar Indonesia.

\section{References}

1. WHO. Quality of care: a process for making strategic choices in health systems. Geneva: World Health Organization. 2006.

2. McLaughlin, C., Johnson, J., \& Sollecito, W. Implementing continuous quality improvement in health care. Sudbury: Jones \& Bartlett Publishers. 2011.

3. Edwards, G. C. Implementing Public Policy. Washington: Congressional Quarterly Press. 1980

4. Geertz, C. The interpretation of cultures (Vol. 5019). New York: Basic books. 1973

5. Othman, A., \& Owen, L. Adopting and measuring customer service quality (SQ) in Islamic banks: a case study in Kuwait finance house. International Journal of Islamic Finanacial Services, 2001. 3(1), $1-26$.
6. Saenong, M. T. Quality of Puskesmas Health Services. Makassar: Nas Media Pustaka. 2019.

7. Latu S, Indar, Maidin A, Darmawansyah, Palutturi S.. Implementation of Family Planning Program Policy Based on Culture in Jayawijaya Province of Papua. Indian Journal of Public Health Research \& Development. Aug 2018.

8. Rosenfeld, S. A. Creating Smart Systems: A Guide to Cluster Strategies in Less Favoured Regions: European Union-regional Innovation Strategies: EUR-OP. 2002.

9. Regulation of the Minister of Health of the Republic of Indonesia Number 75 of 2014 concerning the Center for Public Health, 2014.

10. Creswell, J. W., \& Creswell, J. D.. Research Design: Qualitative, Quantitative, and Mixed Methods Approaches: Sage publications. 2017.

11. Amqam, H., Thalib, D., Anwar, D., Sirajuddin, S., Mallongi, A. Human health risk assessment of heavy metals via consumption of fish from Kao Bay. Reviews on Environmental Health. 2020; https://doi.org/10.1515/reveh-2020-0023

12. Agus Erwin Ashari, Irma Muslimin, Anwar Mallongi, The Strategy of Directly Observed Treatment Shortcourse (DOTS) Towards Compliance with Treatment of Tb Lung Patients in Tb Lung Mamuju District Hospital, Indonesia. Sys Rev Pharm 2020;11(1):1185-1187.

13. Palutturi, S., Rutherford, S., Davey, P., Chu, C. Comparison between healthy cities and Adipura in Indonesia., Malaysian Journal of Medicine and Health Sciences, 2013; Volume 9, Issue 1, Pages 35-43 